\title{
EXPLORATION AND EXPLOITATION OF KNOWLEDGE: SEEKING OPTIMIZATION IN ORGANIZATIONAL LEARNING
}

\author{
SERKAN GÜRSOY(1)
}

\begin{abstract}
The phenomenon of global competition and the critical importance of knowledge in terms of explore and exploit force organizations to combine and balance different activities and tools in order to be adapting the environment and being sustainable. Not only the characteristics of knowledge but also features of social capital carry the world business from individual actions to group actions in a network and/or cluster. This study is focused on requirements of organization in order to be efficient learner as well as efficient absorber. The contradictions of the having both identities are given in the study in the frame of exploration and exploitation activity.
\end{abstract}

Keywords: Exploration, exploitation, knowledge, learning.

JEL Codes: D83, D85, J21, J24, O30, 031, 035 


\section{BiLGININ EDINIMI VE YORUMLANMASI: ÖRGÜTSEL ÖĞRENMEDE OPTIMIZASYON ARAYIŞI}

\section{öz}

Küresel rekabet olgusu ile -arama ve kullanma anlamında- bilginin kritik önemi, çevreye uyum ve sürdürülebilir olmak adına, örgütleri farklı aktiviteler ve araçları birleştirme ve dengeleme konusunda zorlamaktadır. Yalnızca bilginin karakteri değil, sosyal sermayenin özellikleri de dünya iş piyasasını bir ağ ve/veya küme yapısı içinde bireysel işlemlerden topluluk işlemlerine doğru hareket ettirmektedir. Bu çalışma örgütlerin soğurabildikleri kadar etkin birer öğrenici olabilmeleri için gereksinimleri üzerine yoğunlaşmıştır. Her iki kimliğe birde sahip olmanın doğurduğu çelişkiler çalışmada arama ve kullanma aktiviteleri çerçevesinde verilmiştir.

Anahtar Kelimeler: Bilgi, öğrenme, sürdürülebilirlik, sosyal sermaye.

JEL Kodları: D83, D85, J21, J24, O30, 031, 035 


\section{Introduction}

Especially in last decades, network structures and benefits of being a member in a network are highly discussed in the innovation literature. The rising importance of knowledge which has been used to describe post-industrial societies (Bell, 1973) is the backbone of the discussion in terms of knowledge sharing in organizations. As it is known, knowledge can be imitated or transferred through communication (Zander and Kogut, 1995) but the results differ in accordance with the style of transferring knowledge and actors involved in this process. Individuals, groups and organizations are the main actors of the issue while experience, motivation and trust are the factors influencing affectivity in knowledge transfer. When these factors coupled with national, regional, organizational aspects of the culture, some mechanisms, hierarchies, routines, norms come on the ground in order to comprehend the system of networking.

Besides these notations, knowledge sharing which is also addressed in strategic management literature in accordance with resource based theory is the realization of competitive advantage in sense of establishing conditions which enable the sustainability (Grant, 1991). Resource based view characterizes firm's resources as strategic assets and states resource asymmetries between firms as source of organizational rent (Winter, 1987). However, the knowledge based view states the assumption that organizational knowledge is a main strategic resource to sustain competitive advantage by enabling knowledge creation and application in other words exploration and exploitation). At that point, it is highly important to remember the modes of knowledge transfer as the modes of imitation or learning. The mode of imitation is the out of the concept because of the differences between having knowledge and understanding it. The concept of stickiness (Hippel, 1994) restates the importance of organizational learning in terms of having and understanding knowledge in order to use and valorize.

In the literature, organizational knowledge can be defined as a process through which the knowledge held by individuals is amplified, internalized and externalized as part of an organization's knowledge (Nonaka, 1994). Individuals is crucially important for gaining the knowledge in terms of tacit characteristic of knowledge, however, knowledge transfer is much more than having individuals interacting each other. It requires dynamic interactions between four modes of knowledge conversation; socialization, combination, externalization and internalization (Nonaka, 1994). According to Nonaka (1994) Socialization is the process of transferring tacit knowledge as experiential style. Combination is the process of transferring knowledge from different bodies of codified knowledge held by individuals via meetings and exchanges. Externalization is the process of transposing tacit knowledge to codified knowledge. Internalization is the process of transposing codified knowledge to tacit knowledge. Apart from Nonaka's statements, 
it also stated that organizations can learn from their own experiences or from others' experiences (Levitt \& March, 1988). These modes of transferring knowledge can be supposed as clues in order to comprehend the process and necessity of exploration and exploitation activities together. These activities stand on different organizational routines and capabilities (Lewin et al.,1999) and they are fundamental for the organizations in terms of searching for new knowledge, technology, methods for creation of new products and then using and refinement of existing knowledge, technologies and products (Levinthal and March, 1993). March (1991) describe exploration as an entrepreneurial search process for opportunities which are new for the firm and exploitation as a process of routinized search which upgrade firm's existing set of knowledge and competences without changing nature of firm's activities. The distinction between exploration and exploitation can be clarified as the process of exploitation entails the deepening of firm's core knowledge while exploration implies a process broadening into non-core areas. Both for the exploration and exploitation process, networks and clusters offers opportunities and mechanisms by representing especially social capital (Burt, 1992).

The study is designed as follow; the first part conducts on combination of two elements of innovation as exploration and exploitation. The contradictions and challenges are discussed in line with evolutionary approach. Then the study focuses on organizational learning in sense of making trade-off between these factors. Within the frame of networking structures, the problems and suggestion are presented in this part. Finally, the most critical issue of the matter is discussed in the last section by presenting learning myopia and lock-in argument. Reasons and strategies which are discussed in the literature are presented in this part.

\section{Innovations as Combining Exploration and Exploitation}

General implications derived from literature imply that firms must be effective both in exploration and exploitation in order to innovate. While necessity to survive in long term requires exploration in sense of development of new capabilities, necessity of survive short term requires exploitation in sense of efficient use of current capabilities. Combining both behaviors in a process seems problematic because of that exploitation generally requires preservation of stable organizational structure in firm's assets and capabilities, however, exploration needs changes in structure for new configurations for shifting new standards from existing ones (Noteboom, 2004). At that point, a critical question is how exploration and exploitation build on each other in order to know relations with dominant design and radical ones. Because of the distinction between incremental innovations and radical innovation, it is highly important to distinguish explorative innovations from innovations which exploit existing one. 
Based on these considerations Noteboom (2000) introduce a cycle of discovery involving both exploration and exploitation in a process for all levels: individuals, organizations and innovation systems. It intends to explain the difference between incremental and radical innovation together with the difference between exploration and exploitation. In evolutionary economics, an innovation starts with breaking away from established way of producing in other words technological discontinuity (Nelson and Winter, 1982) leads the creation of new knowledge. Based on this statement, it is proposed by Noteboom (2000), exploration results new knowledge and reduces into dominant design then exploitation starts when a variety of content exist and this cycle presents loop ${ }^{(2)}$ for a technological trajectory Abernathy and Utterback, 1978). When looking the mechanism of this loop, it is useful to remember that new knowledge (i.e. embryonic) base is highly tacit and often placed at local firm level and bounded by people (Nelson and Winter, 1982). The next step of upgrading this knowledge is needed to interact with other firms in order to exchange and learn. Additionally, tacit character of knowledge (especially new one, i.e. embryonic) necessitates cognitive closeness which is often case among existing strong ties and transferring this knowledge is possible when close interaction and sufficient trust occurs between actors. The cognitive closeness can be enabled in densely connected networks offering certain level of trust among its members. However, exploration which presents searching and accessing new knowledge requires new members from the outside of the network especially in fast changing environments. These notions carry the weak ties into the mechanism as other important source of exploration (Granovetter, 1985). Under the light of this consideration it can be argued that strong ties are beneficial for governance but not learning while strength of weak ties offers learning opportunity (Granovetter 1985, Burt 1992). The difficulty which arose in this contradiction in combining exploration and exploitation depends on three structural features of the exploitation system; complexity ${ }^{(3)}$, modularity $^{(4)}$ and the tightness of constraints ${ }^{(5)}$ (Noteboom, 2004). In this frame, as evolutionary view, it can be recognized that selection among new knowledge goes through transmission and differentiation (generalization) and then it cause generation

2 Exploitation starts when exploration reduces and result variety of new content (consolidation) and the next step is opening up to these new varieties of contents to enable them applicable (generalization). Then exploitation causes differentiation by making minor modifications in existing content. These modifications in other words incremental adaptations may require new knowledge after a while. More profound changes need more novel context which can be derived from successful familiar practices (reciprocation) (Noteboom, 2000).

3 The complexity of division of labor, defined as the number of component activities and the density of direct ties of dependence between them. Structure is simple when complexity is low (Noteboom, 2004).

4 The modularity of the system, on the basis of clear and stable constraints on activities, along such ties of dependence, in the form of standards, needed to maintain systemic integrity. The opposite would be ambiguity and variability of constraints, by which activities need to be continually coordinated (Noteboom, 2004).

5 The tightness of constraints, i.e. the scope for variety in contributions from component activities. Structure is loose when tightness is low (Noteboom, 2004). 
of new varieties of knowledge as a result of reciprocation and exploration. Noteboom (2004) states that exploitation is systemic when the structure is complex and tight and it is stand-alone when the structure is simple and loose. Nevertheless, exploration takes place in a part of such structures as networks or cluster while exploitation takes place in production. Since exploration requires organizational disintegration, organizations need to combine a narrow focus for exploitation with a wide focus for exploration. In account of innovation, disintegration is needed to allow variety because of Schumpeterian creative destruction. On the other hand, explorative activities may cause expansion of network together with resulting larger cognitive distance in these newly forming ties in network. According to Dosi et. al. (1997), the opportunities for learning increase when entities come from different cognitive background but it is also stated by Noteboom (2000), when cognitive distance is large, potential for learning is become lower. Noteboom (2000) proposes that such exploration may operate isolated from existing networks because of the requirement of fresh knowledge instead of selective and already known.

All these statement carry the issue to the point of derivation that the more radical innovation may result from the more informal instruments used because of the character of knowledge and its cognitive dimension within the environment which is changing rapidly and is uncertain. Table 1 represents some important characteristics of exploration and exploitation in the frame of innovative actions. The distinctions between exploration and exploitation have been discussed in such frames as given in the table. Each of these frames may require detailed discussion on the issue and its relation with innovation. However, this paper is contact on networking in terms of exploration and exploitation. As it is stated before both for exploration and exploitation, firm's network plays an important role because of that it represents social capital held by partners that complement inhouse capabilities (Coleman, 1988, Burt 1992). 
Table 1:

Key characteristics of exploration and exploitation

\begin{tabular}{|c|c|}
\hline Exploration & Exploitation \\
\hline \multicolumn{2}{|c|}{ Competence } \\
\hline Radical innovation & Incremental innovation \\
\hline Technology oriented & $\begin{array}{l}\text { Product and process ori- } \\
\text { ented }\end{array}$ \\
\hline $\begin{array}{l}\text { Experimentation with } \\
\text { novel combination }\end{array}$ & $\begin{array}{l}\text { Experimentation in orga- } \\
\text { nization }\end{array}$ \\
\hline Tacit knowledge & Codified knowledge \\
\hline \multicolumn{2}{|c|}{ Governance } \\
\hline Spin offs, new entrants & Entrance by incumbents \\
\hline Loose alliances & $\begin{array}{l}\text { Formal alliances, acquisi- } \\
\text { tions }\end{array}$ \\
\hline Limited use of contract & Contracts \\
\hline Relation-based trust & Institution-based trust \\
\hline \multicolumn{2}{|c|}{ Networks } \\
\hline Dense, open networks & $\begin{array}{l}\text { Non-dense, more exclu- } \\
\text { sive networks }\end{array}$ \\
\hline Informal, flexible ties & Formalization \\
\hline $\begin{array}{l}\text { Limited size, high entry } \\
\text { and exit }\end{array}$ & Stabilization \\
\hline Locally embedded & Delocalized \\
\hline \multicolumn{2}{|c|}{ Strength of ties } \\
\hline $\begin{array}{l}\text { High frequency of interac- } \\
\text { tion }\end{array}$ & $\begin{array}{l}\text { Low frequency of interac- } \\
\text { tion }\end{array}$ \\
\hline Short duration & Long duration \\
\hline High(er) openness & Limited openness \\
\hline \multicolumn{2}{|c|}{$\begin{array}{c}\text { Transitional process } \\
\end{array}$} \\
\hline $\begin{array}{l}\text { Divergence in knowledge } \\
\text { and organization }\end{array}$ & $\begin{array}{l}\text { Convergence in knowl- } \\
\text { edge and organization }\end{array}$ \\
\hline $\begin{array}{l}\text { Variety through break-up } \\
\text { of existing networks and } \\
\text { new relations to outsiders }\end{array}$ & $\begin{array}{l}\text { Selection by the institu- } \\
\text { tional environment }\end{array}$ \\
\hline
\end{tabular}

Source: V. Gilsing, B. Nooteboom (2006) 
The network activity of the firm can be summarized in three characteristics; direct ties, indirect ties and the degree of redundancy among these ties (Ahuja, 2000). It is proposed that interacting with direct ties may provide access to complementary knowledge and may become faster firm's innovation process (Dyer and Nobeoka, 2000). Direct ties also lead to decrease in cost and risk of investment for networking activity in terms of exploration and exploitation (Ahuja, 2000). As it is proposed before, exploitation focuses on existing core technologies in order to improve them by upgrading internal competences. In this situation, direct ties are beneficial if it provides expertise which firm needs to improve of its core technologies (Rowley et. al. 2000). On the other hand, exploration implies an expansion of firm's knowledge base and it requires external sources of knowledge. In this situation, direct ties may provide new knowledge more effectively (March, 1991).

\section{Organizational Learning and Tradeoff between Exploration and Exploitation in a Network Structure}

Organizational learning can be described as a mechanism which firms build new capabilities enabling sustainability in new contents. The concept of exploration and exploitation which is highlighted in organizational researches can be distinguished as learning which comprises choice, efficiency and selection (exploitation learning) and learning which comprises search, variation, discovery (exploration learning) (March, 1991). The critical derivation is that exploitation-learning leads to improvements of existing organizational routines while exploration-learning develops entirely new routines.

March (1991) conducts on individuals within the organization loaded with diverse set of beliefs and norms. The organization's knowledge improves if individual's knowledge improves and vice versa. Fast learners who are individuals adapting quickly into the new knowledge cause incremental improvements in organization's knowledge and increases efficiency of organizational learning. On the other hand, fast learners cannot be coping with some set of ideas as competence and routines and they may threat long-run learning. However, slow learners who are individuals don not quickly adopt the new knowledge but they provide to maintain beliefs and enable the organization to explore possible combinations of beliefs. Slow learners cause to increase in quality of organizational knowledge in long run. When individuals are assumed as crucial for the organization, influences on networks among them have to be taken into account in line with small world networks which is discussed in the literature in recent times.

By following the notion of networks of individuals, discussion goes through the typologies of networks in term of the style of interaction or connectivity among individuals. Networks are mostly distinguished into three types in accordance with its density of ties. 
These are compartmentalized networks ${ }^{(6)}$ (low density), strongly connected networks(7) (medium density) and loosely connected networks ${ }^{(8)}$ (high density). Even this taxonomy, the literature generally introduce such other definitions and taxonomies which address almost same descriptions. We need to take into consideration that the only critical separation is density and strength.

According to Uzzi and Spiro (2005), when individuals are structured in a defined clusters, it can help to create and maintain variety of knowledge in the community. Densely connected clusters lead the local transmission of information by enabling multiple pathways between its actors. The actors involved in this dense clustering are assumed to be open and ready to exchange information especially because of shared norms, identity, trust and reciprocity (Ahuja, 2000). Together with information exchange, dense clustering is able to facilitate intense relations within time and improve the ability to transfer tacit knowledge. However, this structure of a cluster may result much of the content transferred within the cluster to become homogeneous and redundant (Burt, 1992). Sparse connectivity among individuals in a cluster may help at that point by preserving variety and cluster may tend to be heterogeneous again. In order to maintain balance between sparse and dense or exploration and exploitation, March (1991) suggest that in

6 Compartmentalized networks: When actors are disconnected from each other, the structure of network cannot provide interaction between learning and innovation which referred as compartments. Within this compartmentalization, it is difficult to interact because of cognitive a distance which is harmful for absorptive capacity of the entity. In compartmentalized networks, there are limited ties among entities and many structural holes (Burt, 1992) and there is a proposition that they have low density. Having low density in networks means that network is open for new entrants as much as possible. When linking this consideration it is highly beneficial for the learning activity in sense of exploration.

7 Strongly connected networks: It is a network structure in which there are many ties and frequent interactions among members. Strong ties enable high frequency of interaction and reciprocity in the structure (Granovetter, 1973 in Rowley et. al. 2000) Strongly connected networks also facilitates setting up trust as social capital (Coleman, 1988) which also presence of shared norms and small cognitive distance enhancing mutual understanding in accordance with the absorptive capacity of the organization. These features of strongly connected networks provide an opportunity for transferring tacit knowledge which is very critical issue for learning organization and innovation (Cohen \& Levinthal 1990, Nooteboom 2000). In an environment involving systemic knowledge, a dense structure provides such advantageous as integration of different disciplines in scope of common understanding, sufficient trust and accessing complementary assets. However, in this structure, there are some barriers for new entrants from outside and it causes inertia (Noteboom, 2000) or lock-in. Within the consideration of exploration and exploitation activity, the network structure of strongly connected leads learning myopia (Levinthal and March, 1993).

8 Loosely connected networks: It is a network structure in which members are connected each other within the existence of lower intensity. The strong ties exist in structure among insiders while weak ties exist among outsiders. It is quite good combination in terms of accessing tacit and codified knowledge from inside and new content from outside. The optimal combination of exploration and exploitation activity can be labeled in these structure because of it offers such central elements of evolutionary approach (Nelson and Winter, 1982) as diversity, variety and sustainability at the same time. On the other hand, when cognitive diversity becomes larger, the effective exploitation activity depends on absorptive capacity becomes lower. Even though the optimality of this structure has been still discussed in the literature, there has been stated a general implication that loosely connected networks provides opportunity for learning and innovation (Noteboom 2000; Malerba 2002). 
this clusters as small world network, division of subgroups with the barriers to diffusion between them may help to avoid a situation called as learning myopia for organization or lock-in for cluster.

In the literature, in line with evolutionary approach, it is stressed that, both existing ties and new ties are strongly important similar with the combination of exploration and exploitation. The advantageous of existing and strong ties is to provide cognitive closeness and trust driving to exchange and complement contents involving largely tacit knowledge. However, as it is proposed before accessing new knowledge necessitates new ties which can be named as outsiders. Firms efforts on exploration by interacting with these outsiders continue till the dominant design emerges then firms focus on improvements of existing products and process by the way of exploitation. In this progress, exploration of new contents slows down and variety decreases together with ties becoming strong. In this progress while the rate of change decreases and knowledge becomes more widely diffused, strong ties cause lower cognitive distance and lead to increase the codification of knowledge. As a result, because of dominant design, the elimination of variety provides stability for a term.

All these consideration posits the message that learning and innovation takes place in a network within the frame of structure of existing ties and new ties. The concept of networking can be distinguished as densely connected ties and loosely coupled ones. The critical issue studied by researcher is relations among entities in terms of intensive, frequent, formal or informal. The differentiation among the style of interaction is a driving mechanism of knowledge transfer within the concept of tacit and knowledge, loops between exploration exploitation and finally organizational learning and the balancing the absorptive capacity and future investments. To comprehend the style of interaction, it is beneficial to conduct on the social networks and structures. Networks which formed as strong and weak ties introduced by Granovetter (1973 in Rowley et. al. 2000) have frequent and intense interaction if it has strong ties. It means that the circulation of the content may be redundant. However, a Weak tie based on relation among individuals is named as loosely coupled networks may have an advantageous in providing access to divergent sources. Burt (1992) propose that efficient network structure is characterized by non-redundant ties within the concept of structural holes. According to Burt (1992), it is not rational to increase the number of linkages within the existing network because of the possibility of accessing same contents. Instead, firms should have invested on nonredundant contacts which can be complementary to existing assets and can be a node in structural hole which can be defined as disconnection between actors in network. Being an entity in this hole may provide opportunities for accessing novel knowledge and information by bridging the ties among critical entities. With respect Granovetter, Burt 
(1992) offers a conceptualization the network as strength of ties and density of them. Efficiency in dense networks can be possible if only enabling the maximization of nonredundant connections gained by new entrants while maintaining existing connections. Apart from Granovettern and Burt, Coleman (1988) states a network structure as a social capital exist among actors. Coleman argues that social structures triggers social capital by enabling the norms to coordinate the relationships. These norms provide proper behaviors in network especially it is a dense network. Because of the social control mechanism such as trust and reputation, firms may prevent themselves from opportunistic behaviors. To sum up Granovetter argues the importance of weak ties increasing the possibility and variety of accessible contents while Burt argues the importance of efficiency and structural holes for the same issue. On the other hand Coleman proposes that the social norms and trust as social capital is critical for interaction in dense structure which is important for the innovation. In the literature, there seems to be no optimal structure of network which differs in their combinations of density and strength. The common argument is that the optimality of any combination is dependent on the environment in which network is embedded.

To set up a link between the structure of network and organizational learning through innovation, it is needed to take into consideration characteristics of cognitive variety and cognitive distance. Cognitive variety refers to divergent individual cognitive frameworks in a network while cognitive distance is about the differences among these individuals (Noteboom, 1999). Density of ties indicates the cognitive variety in a network and provides possibility to access variety. Strength of ties indicates the accessing the content which is potential to absorb. Under the light of these considerations, it is now more clarified that existing ties (dense) and new ties (sparse) are important to explore and exploit knowledge in a network. At that point, it is be clearer to remember weak ties are strongly beneficial for accessing to other networks by the way of linkages with outsiders and these weak ties which has large cognitive distance necessitates building up trust among entities. Firms have to spend special effort and make an investment in mutual understanding for not only setting up trust but also adapt organizational routines, procedures in order to reach mutual absorptive capacity (Cohen and Levinthal, 1990).

To state a brief connection between exploration and exploitation activity and organizational learning within the frame of networking, it is important to note that two forms of organizational learning depend on the organization's absorptive capacity which can be defined as ability to assimilate and apply new knowledge (Cohen and Levinthal, 1990). At that point, it can be argued that an organization's capacity is one of the critical factors determining the ability to learn in order to adapt new conditions. March's (1991) argument which is learning by exploration and exploitation as two forms of organizational 
learning is reintroduced in the literature as generative learning (exploration) and adaptive learning (exploitation) Senge (1992).

\section{Network Strategy within the Existance of Learning Myopia and Lock-in}

In the literature of technology management, one of the popular discussion is turn around the rapid technological changes and behaviors of established companies as response to this change. Characterization of exploration and exploitation as contradicting activities leads one more critical problems unsolved. While renewing inventory, skills and knowledge is necessary to adapt tomorrow, having flexibility, creativity and profitability requires control and stability in competencies in an environment involve uncertainty which can be discussed as complexity, variability and dependency. It is one of the most known arguments that uncertainty results complexity stemming from systemic knowledge which requires shared standards and norms to absorb. To reduce the complexity, network should be designed with exclusive relations in order to gain efficient and better accumulation of tacit knowledge. The variability arises from the changes in environment. Changes in environment force firms to connect outsiders who can carry different cognitive perspectives and divergent sources of knowledge (Granovetter, 1973 cited in Rowley et. al. 2000). Weak ties are optimal solutions for the network if firm needs to adapt changes as much as possible. Finally, networks may results dependency which critically influences possibility of learning and innovation. While uncertainty in a dense network emerges complexity and variety, it also causes dependency on strong ties that may turn into lock-in phenomenon (Noteboom, 2000) over time.

In line with this phenomenon, one of the most critical research issues in this field is about "competence trap" (Leonard-Barton, 1992) or "learning myopia" (Levinthal and March, 1993) which refers to ignored alternatives and opportunities by firms when they have sufficient experience in a technology. It is argued that in the absence of sufficient exploration, too much exploitation of the current technology may cause firm to be locked in terms of new insights in long run. March (1991) introduced a model for organizational learning that describes the tradeoffs between exploration and exploitation. According to this model, exploration provides a variety of knowledge necessary for the organization in order to have long-run learning sustainability while exploitation provides more certain and immediate returns (Levinthal and March, 1993). The arguments in the literature indicate this immediate return which may tend to cause limited learning (myopia) if exploitation is used much more. Levinthal and March (1993) point out this trap that knowledge and the development of capabilities improve immediate performance, but they often simultaneously reduce incentives for and competence with new technologies or paradigms. When considering cognitive frameworks and spatiality, the notion of 
learning myopia can be defined as a situation of knowledge creation in specific paths (Maskel and Malmberg, 2007).

A network strategy which is able to cope with results of uncertainty, myopia and lockin involves trade offs upon the institutional conditions. To experience the optimality of networking strategy, firms have spent efforts to design and balance their connection in terms of density and strength of ties. In other words, firm need to balance between changes and adapt by designing exploitation and exploration strategy.

Setting of exploitation strategy is often conceptualized as the standardization, routinization and stabilization with incremental changes. Dominant design emerges and then market uncertainty decreases. Competition shifts to price competition together with new entrants in the market. Learning exists in the environment as refinement of existing knowledge and improving existing competencies. Consequently, it causes an increase in specialization and production of more specific knowledge within a limited framework. The requirement for breaking opportunities is to improve networks with new ties in line with the elimination of redundant ones. Within the existence of increased codification and reduced uncertainty, competitive pressure necessitates radical innovation overtime. In this respects non-dense but strong ties is highly effective in transferring specialized knowledge and results minor improvements (incremental innovation) but not major (radical). When compared to exploration, environmental uncertainty in exploitation is lower and dependency rest in strong ties. And it leads to tradeoff between ties in order to avoid lock-in. Under these conditions an optimal strategy may be selected for a network as low density but strong ties in terms of durability while lower strength in terms of frequency and mutual openness.

Designing a strategy for exploration can be characterized as reaching novel contents by shifting away from established routines. Learning exists in searching for new contents in variety of potentials. Searching thorough existing strong ties carries the firm deeper understanding but lower novelty. When the uncertainty increases in the environment the need for weak ties become critical. However, firms' resources and times limit the number of new ties (Rowley et. al. 2000). On the other hand, increased number of weak ties cause an increase in cognitive distance which is critical for learning (Noteboom, 2000). In order to adapt the environment, firms need to reach desired mix of strong and weak ties for assessing the better value of existing and new knowledge (Rowley et. al. 2000). 


\section{Conclusion}

The statement discussed in this study for why a balance is necessary between exploration and exploitation requires greater diversity in focusing knowledge, networks, and organizational capabilities. While it is a fact that the vulnerability of exploration is fundamental issue in organizational adaptation, it is critically important to exploitation of knowledge in order to produce and sustain in competitive environment. March (1991) proposes that "Compared to returns from exploitation, returns from exploration are systematically less certain, more remote in time, and organizationally more distant from the locus of action and adaptation". When the phenomenon of exploration and exploitation activity generalized through tacit knowledge versus codified knowledge, dense networks versus sparse networks, strong ties versus weak ties, cognitive closeness versus cognitive distance, formal linkages versus informal linkages and etc. it turns a growing body of literature to comprehend the mechanism. The clues for contradictions and combinations have been stated in the paper in order to be a point of start an empirical examination of the issues. It has been stated that firms have to be set up optimal network structure as well optimal mix of features being flexible and stable. It is possible to find out some suggestions on desired mix of issues; however there is not a consensus on an exact situation. Fast changing and uncertain environment, together with the pressures of competitiveness force firms to adapt their assets and abilities as well as strategies to find and use in order to innovate.

\section{REFERENCES}

Abernathy, William J. and James M. Utterback (1978) "Patterns of Industrial Innovation", Technology Review, 81 (June/July), p.41-47.

Ahuja, Gautam (2000) "Collaboration Networks, Structural Holes and Innovation: A Longitudinal Study", Administrative Science Quarterly, 45(3), p.425-455.

Bell, Daniel (1973) The Coming of the Post-Industrial Society: A Venture in Social Forecasting, New York: Basic.

Burt, Ronald S. (1992) Structural Holes: The Social Structure of Competition, Cambridge: Harvard University Press.

Cohen, Wesley M. and Daniel A. Levinthal (1990) “Absorptive Capacity: A New Perspective on Learning and Innovation", Administrative Science Quarterly, (1990), p.128-152.

Coleman, James S. (1988) "Social Capital in the Creation of Human Capital", American Journal of Sociology, (1988), p.95-120.

Dosi, Giovanni, Franco Malerba, Orietta Marsili and Luigi Orsenigo (1997) “Industrial Structures and Dynamics: Evidence, Interpretations and Puzzles", Industrial and Corporate Change, 6, p.3-24. 
Dyer, Jeffrey H. and Kentaro Nobeoka (2000) "Creating and Managing a High Performance Knowledge Sharing Network: The Case of Toyota", Strategic Management Journal, Special Issue (21), p.345-367.

Gilsing, Victor and Bart Nooteboom (2006) "Exploration and Exploitation in Innovation Systems: The Case of Pharmaceutical Biotechnology", Research Policy, 35(1), p.1-23.

Granovetter, Mark S. (1985) "Economic Action and Social Structure, the Problem of Embeddedness", American Journal of Sociology, 91(3), p. 481-510.

Grant, Robert M. (1991) "The Resource-Based Theory of Competitive Advantage Implications for Strategy Formulation", California Management Review, 33(3), p.114-135.

Hippel, Eric Von (1994) “'Sticky Information' and the Locus of Problem Solving: Implications for Innovation", Management Science, 40(4), p.429-439.

Leonard-Barton, Dorothy (1992) "Core Capabilities and Core Rigidities: A Paradox in Managing New Product Development", Strategic Management Journal, 13(S1), p.111-25.

Lewin, Arie Y., Chris P. Long and Timothy N. Carroll (1999) "The Coevolution of New Organizational Forms", Organization Science, 10(5), p.535-550.

Levinthal, Daniel A. and James, G. March (1993) "The Myopia of Learning", Strategic Management Journal, 14(S2), p.95-112.

Malerba, Franco (2002) "Sectoral Systems of Innovation and Production", Research Policy, 31(2), p.247-264.

March, James G. (1991) "Exploration and Exploitation in Organizational Learning", Organization Science, 2(1), p.71-87.

Maskel, Peter and Anders Malmberg (2007) "Myopia, Knowledge Development and Cluster Evolution", Journal of Economic Geography, 7(5), p.603-618.

Nonaka, Ikujiro (1994) "A Dynamic Theory of Organizational Knowledge Creation", Organization Science, 5(1), p.14-37.

Nooteboom, Bart (1999) "Innovation and Interfirm Linkages: New Implications for Public Policy", Research Policy, 28(8), p. 793-805.

Nooteboom, Bart (2000) Learning and Innovation in Organizations and Economics, Oxford: Oxford University Press.

Nooteboom, Bart (2004) Inter-firm Collaboration, Learning and Networks: An Integrated Approach, London: Routledge.

Nelson, Richard R. and Sidney G. Winter (1982) An Evolutionary Theory of Economic Change, Cambridge: Belknap Press.

Rowley, Tim, Dean Behrens and David Krackhardt (2000) "Redundant Governance Structures: An Analysis of Structural and Relational Embeddedness in the Steel and Semiconductor Industries", Strategic Management Journal, Special Issue 21(3), p.369386. 
Senge, Peter M. (1992) “The Leader's New Work: Building Learning Organizations”, Sloan Management Review, Fall, p.7-23.

Uzzi, Brian and Jarrett Spiro (2005) "Collaboration and Creativity: The Small World Problem", American Journal of Sociology, 111(2), p.447-504.

Winter, Sidney G. (1987) "Knowledge and Competence as Strategic Assets", in The Competitive Challenge: Strategies for Industrial Innovation and Renewal (Ed. D.J. Teece), New York: Ballinger.

Zander, Udo and Bruce Kogut (1995) "Knowledge and the Speed of the Transfer and Imitation of Organizational Capabilities: An Empirical Test", Organization Science, 6(1), p.76-92. 